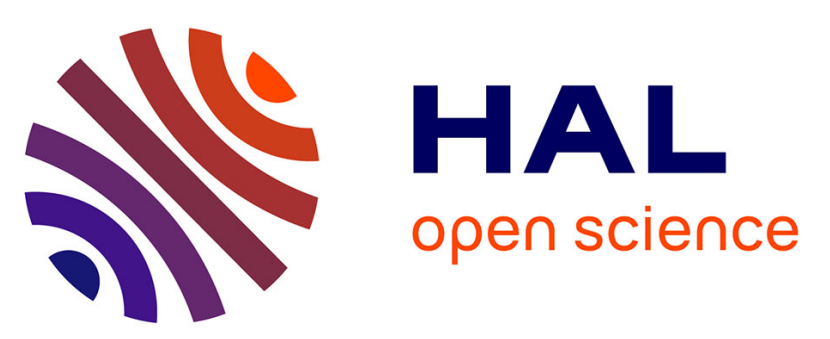

\title{
Complete genome sequence of Methanofervidicoccus sp. A16, a thermophilic methanogen isolated from Mid Cayman Rise hydrothermal vent
}

Liping Wang, Qiliang Lai, Mohamed Jebbar, Zongze Shao, Karine Alain

\section{- To cite this version:}

Liping Wang, Qiliang Lai, Mohamed Jebbar, Zongze Shao, Karine Alain. Complete genome sequence of Methanofervidicoccus sp. A16, a thermophilic methanogen isolated from Mid Cayman Rise hydrothermal vent. Marine Genomics, 2020, 53, pp.100768. 10.1016/j.margen.2020.100768 . hal-02995883

\section{HAL Id: hal-02995883 \\ https://hal.science/hal-02995883}

Submitted on 16 Nov 2020

HAL is a multi-disciplinary open access archive for the deposit and dissemination of scientific research documents, whether they are published or not. The documents may come from teaching and research institutions in France or abroad, or from public or private research centers.
L'archive ouverte pluridisciplinaire HAL, est destinée au dépôt et à la diffusion de documents scientifiques de niveau recherche, publiés ou non, émanant des établissements d'enseignement et de recherche français ou étrangers, des laboratoires publics ou privés. 


\title{
Complete genome sequence of Methanofervidicoccus sp. A16, a thermophilic methanogen isolated from Mid Cayman Rise hydrothermal vent
}

\author{
Liping Wang ${ }^{\mathrm{a}, \mathrm{c}}$, Qiliang Lai ${ }^{\mathrm{a}, \mathrm{c}}$, Mohamed Jebbar ${ }^{\mathrm{b}, \mathrm{c}}$, Zongze Shao ${ }^{\mathrm{a}, \mathrm{c}, *}$, Karine Alain ${ }^{\mathrm{b}, \mathrm{c}, *}$ \\ ${ }^{a}$ Key Laboratory of Marine Genetic Resources, Third Institute of Oceanography, Ministry of Natural Resources of PR China, Xiamen 361005, China \\ ${ }^{\mathrm{b}}$ Univ Brest, CNRS, IFREMER, Laboratoire de Microbiologie des Environnements Extrêmes LM2E, F-29280 Plouzané, France \\ ${ }^{\mathrm{c}}$ LIA1211 MICROBSEA, Sino-French International Laboratory of Deep-Sea Microbiology, Xiamen-Plouzané, France
}

\section{A R T I C L E I N F O}

\section{Keywords:}

Thermophilic

Methanogenesis

Methanofervidicoccus sp.

Hydrothermal vent

\begin{abstract}
A B S T R A C T
Methanofervidicoccus sp. A16 is a novel thermophilic and obligate hydrogenotrophic methanogen isolated from a deep-sea hydrothermal vent chimney sample at the Mid Cayman spreading center, Caribbean Sea. Here we report the complete genome of strain A16, which has one circular chromosome of 1,485,358 bp with a mean G + C content of $35.01 \mathrm{~mol} \%$. The complete genome harbors 1442 predicted protein-encoding genes. Genes involved in hydrogenotrophic methane production and $\mathrm{N}_{2}$ fixation were identified in this genome. This study expands our knowledge of methanogenesis at high temperatures and the involvement of these microorganisms in the carbon and nitrogen cycles of deep-sea hydrothermal environments.
\end{abstract}

\section{Introduction}

Methanogenic archaea are strictly anaerobic prokaryotes that are widely distributed in anoxic environments such as wetlands, paddy fields, sediments and digestive tracts (Thauer et al., 2008). They produce methane as the terminal step of organic matter fermentation. Of the 500-600 million tons of methane released into the atmosphere each year, $69 \%$ originate from microbial metabolism (Conrad, 2009). Methanogens can use carbon dioxide and $\mathrm{H}_{2}$, simple carbon compounds (acetate, formate, etc) or methylated compounds (methylamine, dimethylsulfide, choline, etc) as energy and carbon sources, and produce methane as a metabolic waste product. Nowadays, a number of hyperthermophilic or thermophilic methanogenic archaea belonging to the order Methanococcales have been isolated from a variety of marine hydrothermal environments, including Methanococcus igneus $\mathrm{Kol} 5^{\mathrm{T}}$, Methanotorris formicicus Mc-S- $70^{\mathrm{T}}$, Methanothermococcus okinawensis $\mathrm{IH} 1^{\mathrm{T}}$, Methanococcus jannaschii DSM $2661^{\mathrm{T}}$, Methanocaldococcus infernus $\mathrm{ME}^{\mathrm{T}}$, Methanocaldococcus indicus SL43 ${ }^{\mathrm{T}}$, Methanocaldococcus villosus KIN24-T80 ${ }^{\mathrm{T}}$, Methanocaldococcus bathoardescens $\mathrm{JH} 146^{\mathrm{T}}$ and further species (Jones et al., 1983; Burggraf et al., 1990; Jeanthon et al., 1998; Takai et al., 2002; L'Haridon et al., 2003; Takai et al., 2004; Bellack et al., 2011; Stewart et al., 2015).

The A16 genome sequence and its annotation is reported in the study. Strain A16 was isolated from a deep-sea hydrothermal vent chimney sample collected in a depth of $2295 \mathrm{~m}$ from Von Damm vent field (Hole to Hell site) $\left(18^{\circ} 22.6007^{\prime} \mathrm{N}, 81^{\circ} 47.8909^{\prime} \mathrm{W}\right)$ at the Mid Cayman spreading center, Caribbean Sea. It was enriched and purified in DSM 141 medium, at $70{ }^{\circ} \mathrm{C}$, under an atmosphere of $\mathrm{H}_{2} / \mathrm{CO}_{2}(80 / 20$, $0.2 \mathrm{MPa}$ ). Strain A16 was identified as a potential novel species of the genus Methanofervidicoccus, with highest 16S rRNA sequence similarity of $98.6 \%$ to Methanofervidicoccus abyssi $\mathrm{HHB}^{\mathrm{T}}$, which was reported recently as a novel methanogen belonging to the order Methanococcales (Sakai et al., 2019). Strain A16 is an obligate anaerobic archaeon that can use $\mathrm{CO}_{2}$ and $\mathrm{H}_{2}$ as the sole carbon and energy sources to produce $\mathrm{CH}_{4}$.

\section{Data description}

Genomic DNA of strain A16 was extracted with the QIAGEN Genomic-tip 20/G (QIAGEN, Düsseldorf, Germany) kit following the manufacturer's standard protocol. The complete genome sequence of strain A16 was determined by Shanghai Majorbio Bio-pharm Technology Co., Ltd. (Shanghai, China), using the PacBio RSII platform (Table 1). For whole genome sequencing, a $10 \mathrm{~kb}$ DNA fragment library was constructed and sequenced on the PacBio RSII sequencing platform, with one SMRT cell (MajorBio Co., Shanghai, China). After quality control, reads were assembled by HGAP 3.0 (Chin et al., 2013). Gene prediction was performed using Glimmer version 3.02 (http://

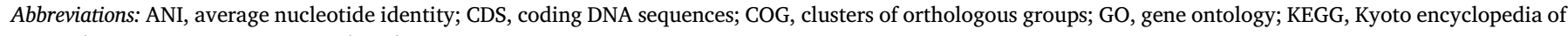
genes and genomes; ORFs, open reading frames

* Corresponding authors at: LIA1211 MICROBSEA, Sino-French International Laboratory of Deep-Sea Microbiology, Xiamen-Plouzané, France.

E-mail addresses: shaozz@163.com (Z. Shao), Karine.Alain@univ-brest.fr (K. Alain).
} 
Table 1

General features of Methanofervidicoccus sp. A16.

\begin{tabular}{ll}
\hline Items & Description \\
\hline $\begin{array}{l}\text { General features } \\
\text { Superkingdom }\end{array}$ & Archaea \\
Strain & Methanofervidicoccus sp. A16 \\
Geographic location & Atlantic Ocean: Caribbean Sea, Von Damm vent field \\
& (Hole to Hell site) at the Mid Cayman spreading center \\
Sample type & deep-sea hydrothermal vent chimney sample \\
Latitude and longitude & $18^{\circ} 22.6007^{\prime}$ N, $81^{\circ} 47.8909^{\prime}$ W \\
Depth & -2295 m \\
Collection date & June 2013 \\
Biotic relationship & Free-living \\
Genome characteristics & \\
Sequencing platform & PacBio RSII \\
Assembly method & HGAP 3.0 \\
Genome coverage & $650 \times$ \\
Finishing quality & Complete genome \\
NCBI accession number & CP022242 \\
BioProject & PRJNA391986 \\
BioSample & SAMN07281457 \\
Size (bp) & $1,485,358$ \\
DNA G + C content (\%) & 35.01 \\
CDSs & 1422 \\
tRNAs & 34 \\
16S-23S-5S rRNAs & $2-2-2$ \\
\hline & \\
\hline & \\
&
\end{tabular}

cbcb.umd.edu/software/glimmer/). In addition, rRNA and tRNA genes were identified using Barrnap 0.4.2 and tRNA scan-SE v1.3.1 softwares. Functional annotation was performed using NCBI prokaryotic genome annotation pipeline (Tatusova et al., 2016), the Rapid Annotation using Subsystem Technology (RAST) pipeline (http://rast.nmpdr.org/) (Overbeek et al., 2014), and the the MicroScope Microbial Genome
Annotation and Analysis Platform (MaGe) (Vallenet et al., 2009). Deduced gene products were blasted against KEGG, COG, String and GO databases.

The complete genome of the strain A16 consists of a single circular chromosome with a total length of $1,485,358$ bp and an average $\mathrm{G}+\mathrm{C}$ content of $35.01 \mathrm{~mol} \%$ (Fig. 1). A total of 1442 protein-coding sequences (CDSs) were predicted, with a summed up gene length of $1,178,139 \mathrm{bp}$, giving a coding intensity of $78.71 \%$. Majority of the CDSs (1206/1422, 84.81\%) could be assigned to a putative function according to COG categories, while the rest were annotated as hypothetical proteins. 34 tRNA genes for 21 amino acids, two 5S rRNAs, two 16S rRNA, two 23S rRNA, 2 miscellaneous RNAs (misc RNA) and 2 pseudogenes were also identified in the genome.

Strain A16 can use $\mathrm{H}_{2}$ as electron donor and $\mathrm{CO}_{2}$ as carbon source for growth and produce $\mathrm{CH}_{4}$. Genes coding for the full pathway of hydrogenotrophic methanogenesis were identified in the genome, which included formylmethanofuran dehydrogenase (Fwd, CFE53_04850, CFE53_05015, CFE53_06085, CFE53_06090, CFE53_06095, CFE53_06100, CFE53_06105, and CFE53_06110), formylmethanofuran-tetrahydromethanopterin N-formyltransferase (Ftr, CFE53_06700), N5, N10-methenyltetrahydromethanopterin cyclohydrolase (Mch, CFE53_06735), $\mathrm{F}_{420}$-dependent methylenetetrahydromethanopterin dehydrogenase (Mtd, CFE53_05635), $\mathrm{F}_{420}$-dependent N5, N10-methylenetetrahydromethanopterin reductase (Mer, CFE53_02485), N5-methyltetrahydromethanopterin: coenzyme M methyltransferase (Mtr, CFE53_01150, CFE53_01155, CFE53_01160, CFE53_01170, CFE53_01175, CFE53_01180, CFE53_01185), Methyl coenzyme M reductase (Mcr, CFE53_01190, CFE53_01195, CFE53_01200, CFE53_01205 and CFE53_01210), and heterodisulfide reductase (Hdr, CFE53_02215, CFE53_06410, CFE53_06415, CFE53_06755 and CFE53_06760) (Table S1).

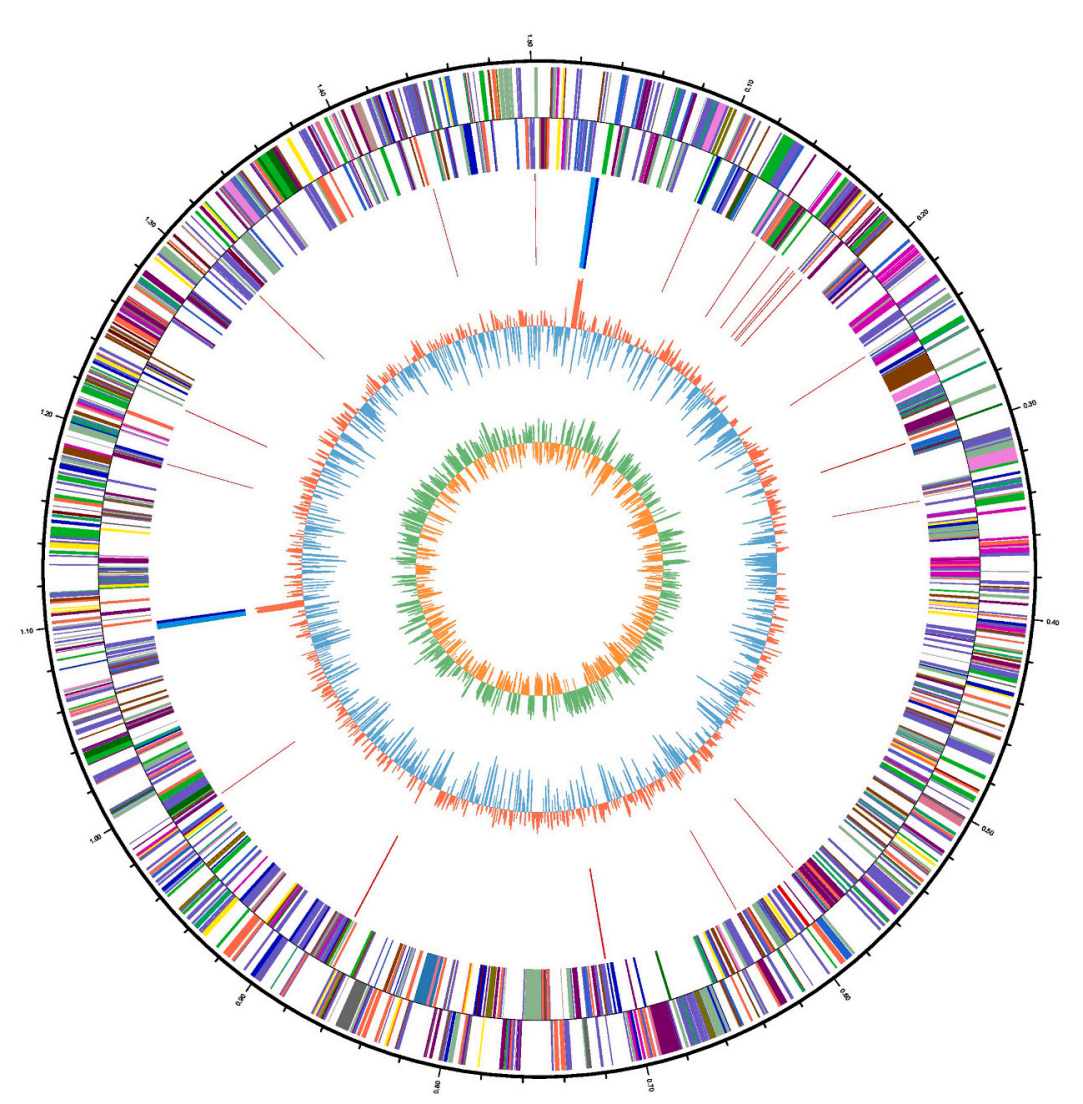

NON-Coding RNA categories

tRNA

5S_rRNA

16S_rRNA

23S_rRNA

COG Functional categories

A: RNA processing and modification

B: Chromatin structure and dynamics

$\square$ C: Energy production and conversion

$\square$ D: Cell division and chromosome partitioning

$\square$ E: Amino acid transport and metabolism

F: Nucleotide transport and metabolism

$\square$ G: Carbohydrate transport and metabolism

$\square$ H: Coenzyme metabolism

$\square$ I: Lipid metabolism

$\mathrm{J}$ : Translation, ribosomal structure and biogenesis

$\square$ K: Transcription

$\square$ L: DNA replication, recombination, and repair

$\square$ M: Cell envelope biogenesis, outer membrane

$\square \mathrm{N}$ : Cell motility and secretion

$\square$ O: Posttranslational modification, protein turnover chaperones

$P$ : Inorganic ion transport and metabolism

Q: Secondary metabolites biosynthesis, transport and catabolism

$\square$ R: General function prediction only

$\square$ S: Function unknown

$\square$ T: Signal transduction mechanisms

$\square$ U: Intracellular trafficking, secretion, and vesicular transport

$\square$ V: Defense mechanisms

$\square$ No assigned COG

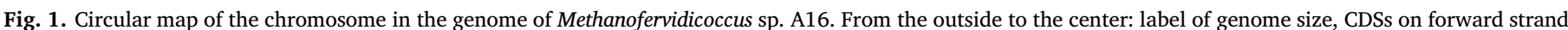

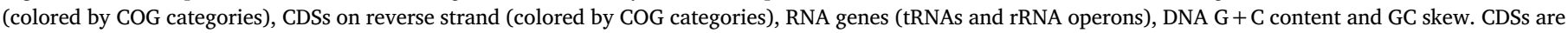
depicted in different colors according to COG categories. 


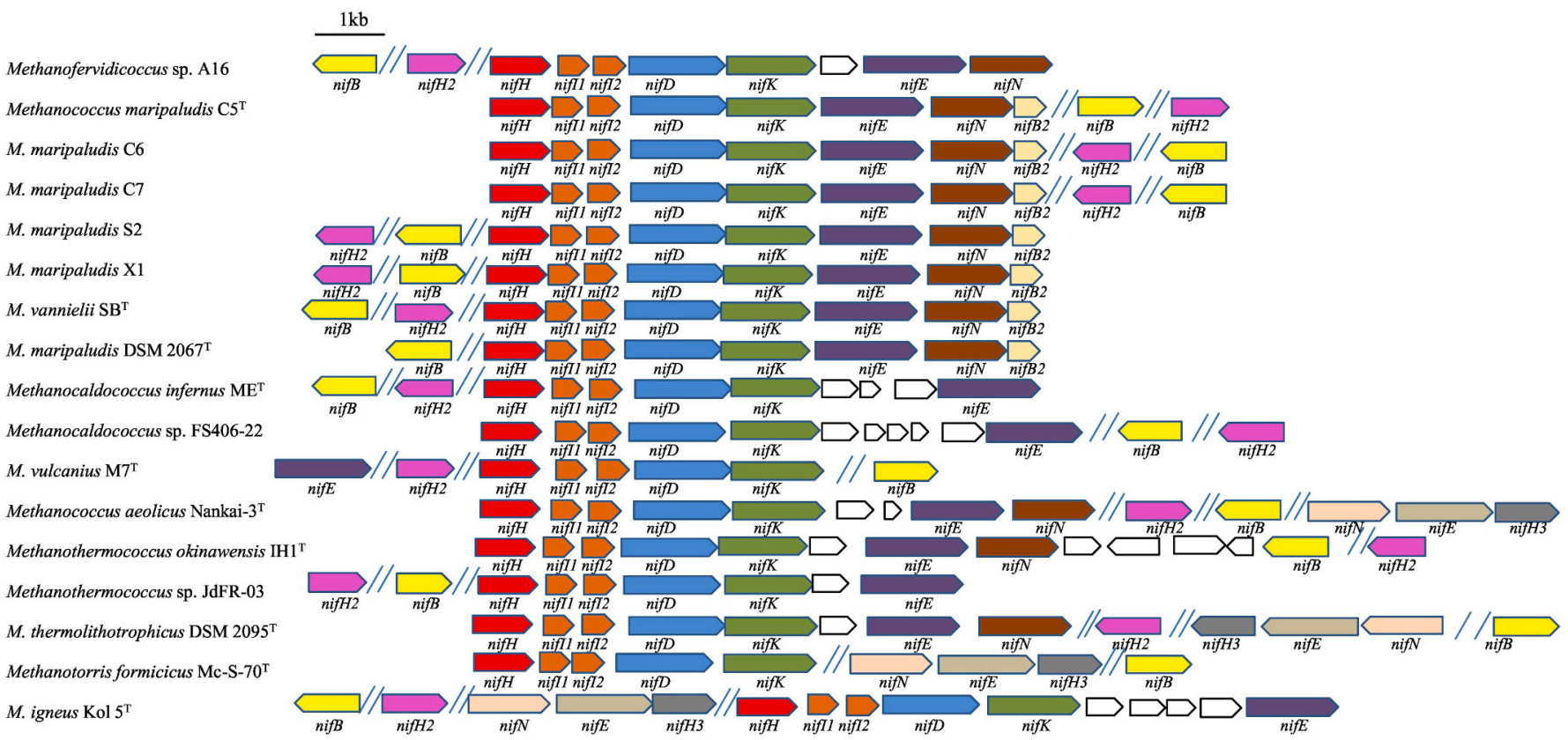

Fig. 2. Comparison analysis of the nitrogen fixation gene arrangement based on the genomes of Methanofervidicoccus sp. A16 and other sixteen methanogens within the order Methanococcales.

At the time of writing, twenty-three genomes belonging to the order Methanococcales were available in the NCBI and JGI databases. Based on core genome analysis, strain A16 featured the closest phylogenetic relationship to Methanofervidicoccus abyssi $\mathrm{HHB}^{\mathrm{T}}$ (Fig. S1). The average nucleotide identity (ANI) value between strain $\mathrm{A} 16$ and $\mathrm{HHB}^{\mathrm{T}}$ were $85.2 \%$, which was below standard ANI criteria for species identity (95-96\%) (Richter and Rosselló-Mora, 2009). Further genome sequence analysis of strain A16 revealed 116 unique genes mainly involved in Energy production and conversion, Amino acid transport and metabolism, Replication, recombination and repair, Cell wall, membrane and envelope biogenesis and Inorganic ion transport and metabolism, when compared with $\mathrm{HHB}^{\mathrm{T}}$ (Table S2). A minimum set of six genes, nifH (CFE53_01675), nifD (CFE53_01660), nifK (CFE53_01655), nifE (CFE53_01645), nifN (CFE53_01640) and nifB (CFE53_05660), coding for structural and biosynthetic components of nitrogenase (Santos et al., 2012) are present in the A16 genome, while these are absent in strain $\mathrm{HHB}^{\mathrm{T}}$. In additon, two genes (CFE53_01665 and CFE53_01670) coding for nitrogen-fixation associated regulatory protein P-II are also located in this gene cluster. Comparative genome analyses further showed that the gene cluster for nitrogen fixation also exists in other sixteen strains of the order Methanococcales, although they show some differences in gene synteny, as shown in Fig. 2 and Fig. S1. Among these strains, Methanothermococcus thermolithotrophicus DSM $2095^{\mathrm{T}}$ (Belay et al., 1984; Leigh, 2000), Methanococcus maripaludis DSM $2067^{\mathrm{T}}$ (Blank et al., 1995), M. maripaludis S2 (Kessler et al., 1998; Santos et al., 2012), Methanococcus aeolicus Nankai- $3^{\mathrm{T}}$ (Kendall et al., 2006), Methanotorris formicicus Mc-S-70 ${ }^{\mathrm{T}}$ (Takai et al., 2004) and Methanocaldococcus sp. FS406-22 (Mehta and Baross, 2006), have been reported as diazotrophic methanogens. In this study, the genome analysis of strain A16 will help to understand the ecological role of this species in carbon and nitrogen cycle in submarine hydrothermal environments.

\section{Nucleotide sequence accession number}

The complete genome sequence of Methanofervidicoccus sp. A16 has been deposited in the GenBank database under number CP022242. The strain is available from the Universite de Bretagne Occidentale Culture Collection under number UBOCC-M-3304.

\section{Declaration of Competing Interest}

The authors declare that they have no known competing financial interests or personal relationships that could have appeared to influence the work reported in this paper.

\section{Acknowledgments}

We are very grateful to the YK13-05 cruise operation teams for helping us to collect the hydrothermal samples and to the chief scientist Ken Takai. We thank Stéphane L'Haridon for the isolation of the strain. This work was supported by the PHC Cai Yuanpei Provirvent $\left(\mathrm{N}^{\circ}\right.$ 34634WE), the program MERLIN Abyss, the LIA 1211 MicrobSea and the "Laboratoire d'Excellence" LabexMER (ANR-10-LABX-1), National Key R\&D Program of China (No. 2018YFC0310701), National Natural Science Foundation of China (No. 41506152).

\section{Appendix A. Supplementary data}

Supplementary data to this article can be found online at https:// doi.org/10.1016/j.margen.2020.100768.

\section{References}

Belay, N., Sparling, R., Daniels, L., 1984. Dinitrogen fixation by a thermophilic methanogenic bacterium. Nature 312, 286-288.

Bellack, A., Huber, H., Rachel, R., Wanner, G., Wirth, R., 2011. Methanocaldococcus villosus sp. nov., a heavily flagellated archaeon that adheres to surfaces and forms cell-cell contacts. Int. J. Syst. Evol. Microbiol. 61, 1239-1245.

Blank, C., Kessler, P.S., Leigh, J.A., 1995. Genetics in methanogens: transposon insertion mutagenesis of a Methanococcus maripaludis nifH gene. J. Bacteriol. 177, 5773-5777.

Burggraf, S., Fricke, H., Neuner, A., Kristjansson, J.K., Rouvier, P., Mandelco, L., et al., 1990. Methanococcus igneus sp. nov., a novel hyperthermophilic methanogen from a shallow submarine hydrothermal system. Syst. Appl. Microbiol. 13, 263-269.

Chin, C., Alexander, D.H., Marks, P., Klammer, A., Drake, J.P., Heiner, C., et al., 2013. Nonhybrid, finished microbial genome assemblies from long-read SMRT sequencing data. Nat. Methods 10, 563-569.

Conrad, R., 2009. The global methane cycle: recent advances in understanding the microbial processes involved. Environ. Microbiol. Rep. 1, 285-292.

Jeanthon, C., L'Haridon, S., Reysenbach, A.L., Vernet, M., Messner, P., Sleytr, U.B., Prieur, D., 1998. Methanococcus infernus sp. nov., a novel hyperthermophilic lithotrophic methanogen isolated from a deep-sea hydrothermal vent. Int. J. Syst. Bacteriol. 48, 
913-919.

Jones, W.J., Leigh, J.A., Mayer, F., Woese, C.R., Wolfe, R.S., 1983. Methanococcus jannaschii sp. nov., an extremely thermophilic methanogen from a submarine hydrothermal vent. Arch. Microbiol. 136, 254-261.

Kendall, M.M., Liu, Y., Sieprawskalupa, M., Stetter, K.O., Whitman, W.B., Boone, D.R., 2006. Methanococcus aeolicus sp. nov., a mesophilic, methanogenic archaeon from shallow and deep marine sediments. Int. J. Syst. Evol. Microbiol. 56, 1525-1529.

Kessler, P.S., Blank, C., Leigh, J.A., 1998. The nif gene operon of the methanogenic archaeon Methanococcus maripaludis. J. Bacteriol. 180, 1504-1511.

Leigh, J.A., 2000. Nitrogen fixation in methanogens: the archaeal perspective. Curr. Iss. Mol. Biol. 2, 125-131.

L'Haridon, S., Reysenbach, A.L., Banta, A., Messner, P., Schumann, P., Stackebrandt, E., Jeanthon, C., 2003. Methanocaldococcus indicus sp. nov., a novel hyperthermophilic methanogen isolated from the Central Indian Ridge. Int. J. Syst. Evol. Microbiol. 53, 1931-1935.

Mehta, M.P., Baross, J.A., 2006. Nitrogen fixation at 92 degrees C by a hydrothermal vent archaeon. Science 314, 1783-1786.

Overbeek, R.A., Olson, R., Pusch, G.D., Olsen, G.J., Davis, J.J., Disz, T., et al., 2014. The SEED and the Rapid Annotation of microbial genomes using Subsystems Technology (RAST). Nucleic Acids Res. 42, 206-214.

Richter, M., Rosselló-Mora, R., 2009. Shifting the genomic gold standard for the prokaryotic species definition. Proc. Natl. Acad. Sci. U. S. A. 106, 19126-19131.

Sakai, S., Takaki, Y., Miyazaki, M., Ogawara, M., Yanagawa, K., Miyazaki, J., Takai, K., 2019. Methanofervidicoccus abyssi gen. nov., sp. nov., a hydrogenotrophic methanogen, isolated from a hydrothermal vent chimney in the Mid Cayman spreading center, the Caribbean Sea. Int. J. Syst. Evol. Microbiol. 69, 1225-1230.

Santos, P.C.D., Fang, Z., Mason, S.W., Setubal, J.C., Dixon, R., 2012. Distribution of nitrogen fixation and nitrogenase-like sequences amongst microbial genomes. BMC Genomics 13, 162.

Stewart, L.C., Jung, J.H., Kim, Y.T., Kwon, S.W., Park, C.S., Holden, J.F., 2015 Methanocaldococcus bathoardescens sp. nov., a hyperthermophilic methanogen isolated from a volcanically active deep-sea hydrothermal vent. Int. J. Syst. Evol. Microbiol. 65, 1280-1283.

Takai, K., Inoue, A., Horikoshi, K., 2002. Methanothermococcus okinawensis sp. nov., a thermophilic, methane-producing archaeon isolated from a Western Pacific deep-sea hydrothermal vent system. Int. J. Syst. Evol. Microbiol. 52, 1089-1095.

Takai, K., Nealson, K.H., Horikoshi, K., 2004. Methanotorris formicicus sp. nov., a novel extremely thermophilic, methane-producing archaeon isolated from a black smoker chimney in the Central Indian Ridge. Int. J. Syst. Evol. Microbiol. 54, 1095-1100.

Tatusova, T., Dicuccio, M., Badretdin, A., Chetvernin, V., Nawrocki, E.P., Zaslavsky, L. et al., 2016. NCBI prokaryotic genome annotation pipeline. Nucleic Acids Res. 44, 6614-6624.

Thauer, R.K., Kaster, A., Seedorf, H., Buckel, W., Hedderich, R., 2008. Methanogenic archaea: ecologically relevant differences in energy conservation. Nat. Rev. Microbiol. 6, 579-591.

Vallenet, D., Engelen, S., Mornico, D., Cruveiller, S., Fleury, L., Lajus, A., et al., 2009. MicroScope: a platform for microbial genome annotation and comparative genomics. Database 2009. 